\title{
A finite element model of semi-rigid mortise-and-tenon joint considering glue line and friction coefficient
}

\author{
Wengang Hu and Huiyuan Guan*
}

\begin{abstract}
The aim of this study is to build a new numerical model of a mortise-and-tenon joint based on the finite element method (FEM) considering glue line and friction coefficient to analyze the semi-rigid wood joint. Firstly, the friction coefficient, glue distributions and strengths of the mortise-and-tenon joint were determined by experimental methods. Secondly, these parameters were specified to a T-shaped mortise-and-tenon joint model to build a finite element model of joint by FEM. Finally, both withdrawal and bending load capacity of T-shaped specimens were investigated by experimental and numerical methods. The results showed that the testing methods used to determine the coefficient, distributions and strengths of the glued mortise-and-tenon joint were all effective enough to determine the mechanical properties of the wood mortise-and-tenon joint, and the finite element model of joint can be applied to analyze the semi-rigid mortise-and-tenon joint with consistency beyond $85 \%$. These methods and finite element models will contribute to the analysis of wood products and wood constructions.
\end{abstract}

Keywords: Finite element model, Semi-rigid, Wood framework, Glue line, Friction coefficient

\section{Introduction}

Mortise-and-tenon joint is widely used in wood products and wooden constructions engineering [1,2]. It is well known that the joints are critical part of wood frameworks [3-5]. Besides, it is a typical semi-rigid joint manufactured by wood. It was first introduced into stiffness evaluation of furniture joint by Eckelman [6]. Generally, it is difficult to evaluate the strength of a semi-rigid joint accurately by normal knowledge of mechanics. However, with the development of computer technique, the finite element method (FEM) has been popular with engineers and applied to structure design of wooden constructions and wood products. Although a number of studies have focused on this topic, the methods of modeling a reasonable semi-rigid mortise-and-tenon joint by FEM has not been figured out.

The mortise-and-tenon joint was regarded as a rigid joint in some studies $[7,8]$ using FEM to analyze the

*Correspondence: hwg@njfu.edu.cn

College of Furnishings and Industrial Design, Nanjing Forestry University, Nanjing 210037, China skeletal furniture. Obviously, although this can simplify the model, the results were not accurate enough to analyze the whole frame of furniture. Also, others considered it as semi-rigid by taking glue line into consideration when building finite element model of joint by FEM. However, the joint is usually assumed as a clearance fit and the gap is equal to the clearance [9-12]. In addition, the mortise-and-tenon joint was seen as a semi-rigid connection by adding a spring which was predefined by spring constant value [13]. These studies contributed to analyze semi-rigid joint by FEM, but further studies must been conducted to make it more accurate. Džinčić and Živanić [14] studied the distributions of glue in the joint with entire clearance and total interference fit by metallographic microscope. The results showed that, with $0.1 \mathrm{~mm}$ clearance fit, the glue line was clear and not interrupted along the tenon, and the average thickness of joint was $0.095 \mathrm{~mm}$. By contrast, with interference fit, no glue was observed but only the compressed wood, because the glue in the interference fit area was squeezed out. However, in factual industrial practice, the real-time manufacturing condition of the mortise-and-tenon joint 
is both with interference fit and clearance fit at the same time (i.e., the interference fit in wide direction of tenon, and clearance fit in thick direction of tenon). Thus, the distributions of glue in real-time condition should be determined, and a reasonable model of the mortise-andtenon joint must take these points into consideration.

In this study, the concept of the semi-rigid mortiseand-tenon joint can be explanted as the effects of glue line, friction coefficient and the strength of wood itself. So it is vitally important to know more about the distributions of glue, the friction coefficient of joint and mechanical properties of wood before building the model of joint. In addition, the mechanical properties of joint inputted into the finite element model must be determined and assigned to a model with appropriate finite elements.

The aim of this study was to further investigate the distributions of glue and friction coefficient of joint considering the real-time condition of joint by experimental methods, and build a finite element model of mortise-and-tenon joint based on the results determined by experiments. In addition, a comparison was made between the results of FEM and experiment to verify the validity of the finite element model through determining withdrawal and bending resistance loading capacity of T-shaped mortise-and-tenon joint specimens.

\section{Materials and methods}

\section{Materials}

All of the specimens were made with beech (Fagus orientalis. Lipsky), bought from local wood commercial supplier (Nanjing, China). According to the ASTM D 4442 [15], the average density was $0.692 \mathrm{~g} / \mathrm{cm}^{3}$, and the moisture content of beech was conditioned to and held at $10.8 \%$ before and during the experiment. Besides, the joint was glued with polyvinyl acetate (PVAc), which was produced by Pattex, and the solid content was $52 \%$. In addition, the temperature was controlled at $22{ }^{\circ} \mathrm{C}$, and the relative humidity was $48 \%$ during the whole process of experiment.

\section{Specimen preparation}

Figure 1 shows the general configurations of a T-shaped mortise-and-tenon joint specimen used in this study. The joint consists of a stretcher with its end attached to a post through round-end mortise-and-tenon construction applied with PVAc adhesive of $52 \%$ solids content. The stretcher measured $120 \mathrm{~mm}$ long $\times 40 \mathrm{~mm}$ wide $\times 30 \mathrm{~mm}$ thick. The post measured $150 \mathrm{~mm}$ long $\times 40 \mathrm{~mm}$ wide $\times 30 \mathrm{~mm}$ thick. All joint members were prepared from quarter-sawn lumber. The mortise measured $16 \mathrm{~mm}$ wide $\times 30 \mathrm{~mm}$ high $\times 30 \mathrm{~mm}$ deep. Besides, the difference between height of mortise and width of tenon was $0.2 \mathrm{~mm}$ interference fit, while the width of mortise and thickness of tenon was $0.2 \mathrm{~mm}$ clearance fit.

Figure 2 presents the dimensions of specimen to determine the friction coefficient of joint in front view (Fig. 2a), left view (Fig. 2b) and top view (Fig. 2c) respectively. The mortise was divided into two same parts, and the lower parts of the tenons were glued to the lower parts of mortises, while the upper parts were free. In addition, the specimen was processed as a double

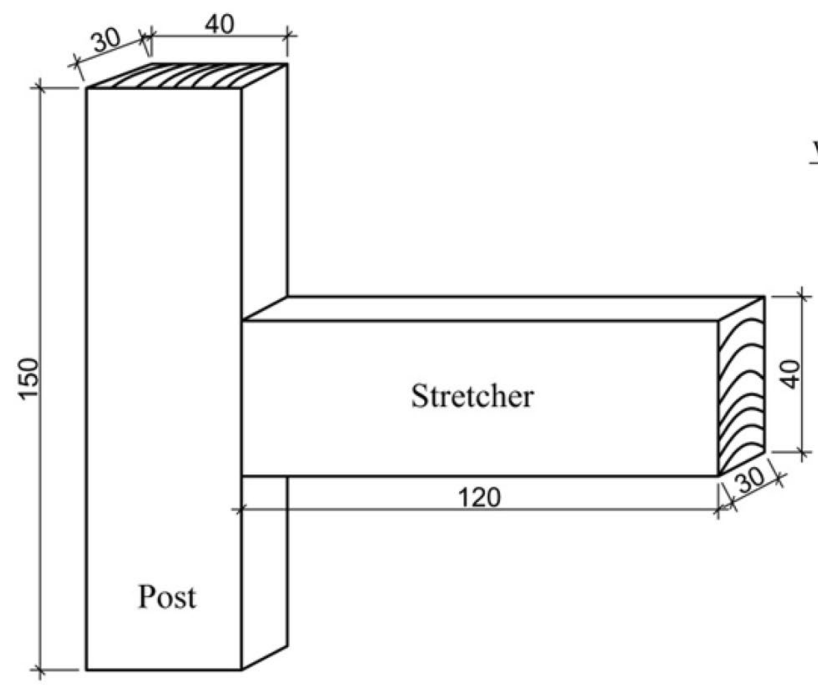

a

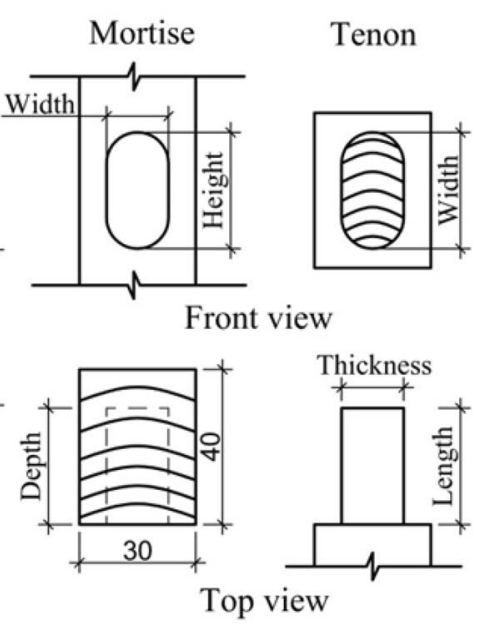

b Unit: $\mathrm{mm}$

Fig. 1 Dimensions of the T-shaped specimen (a) and the mortise-and-tenon joint (b) 


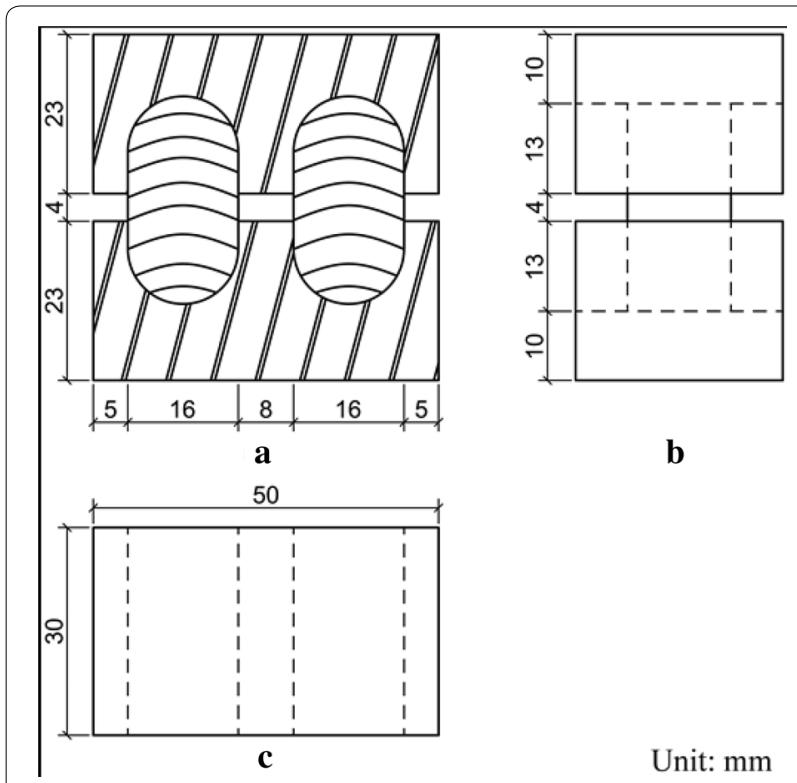

Fig. 2 Sizes of the specimen used to determine the friction coefficient of the mortise-and-tenon joint. a Front view, b left view, c top view

mortise-and-tenon joint to make it balance, when the upper part of mortises moved upon the tenons. In addition, the effect of grain orientations of tenon on friction coefficient was studied. Figure 2 only shows the tenon in radial grain orientation.
Figure 3a illustrates the method of cutting the specimens to determine the distributions of glue in the joint and the shear strengths of the joint. All of the specimens were cut from the glued joint directly to confirm the determining results were consistent with the real condition of joint. Figure $3 \mathrm{~b}, \mathrm{c}$ shows the specimens used to process the slices to measure the distributions of glue in the curve surface and flat surface of the joint, respectively. In addition, Fig. 3c was used to test the internal bond strength of glue joint in the flat area. Figure $3 \mathrm{~d}$ presents the dimensions and grain orientations of specimen to determine the shear strength of the joint in withdrawal direction $\left(G_{I}\right)$, and Fig. 3e shows the specimen to determine the shear strength of the joint perpendicular to the withdrawal direction $\left(G_{\mathrm{II}}\right)$. These parameters will be used in finite element model.

\section{Testing methods}

\section{Friction coefficient of the joint}

Figure 4 shows the setup to measure the friction coefficient of the mortise-and-tenon joint. The specimens (Fig. 2) were put into the specimen groove and loaded by counterweight. Then the load was imposed through a steel wire by a universal testing machine with loading ratio $1 \mathrm{~mm} / \mathrm{min}$. A total of 20 specimens were determined, and then the friction coefficient can be figured out by Eq. 1.

$$
\mu=\frac{F p}{\left(m_{1}+m_{2}\right) g},
$$

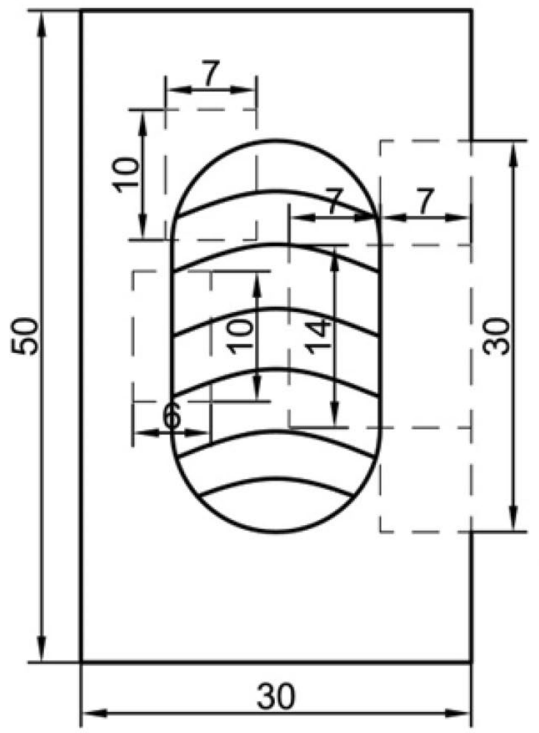

a
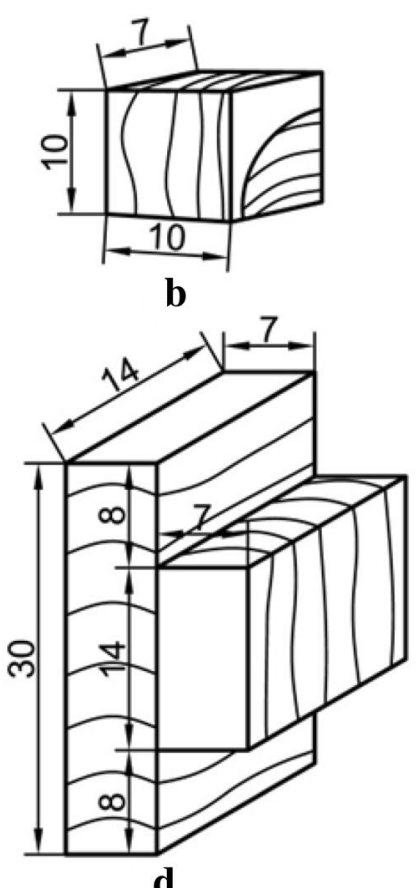

d
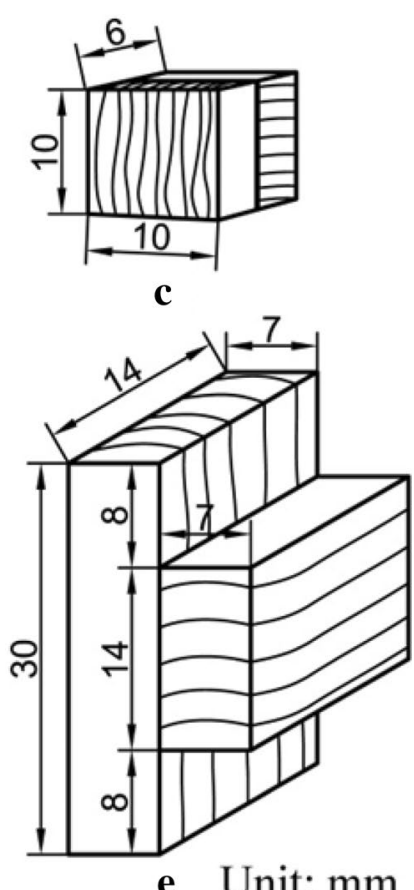

e Unit: $\mathrm{mm}$

Fig. 3 Cutting patterns of the joint (a) to measure the distributions of glue in curve surface (b) and flat surface (c), and shear strength of $G_{l}(\mathbf{d})$ and $G_{\|}(\mathbf{e})$ 


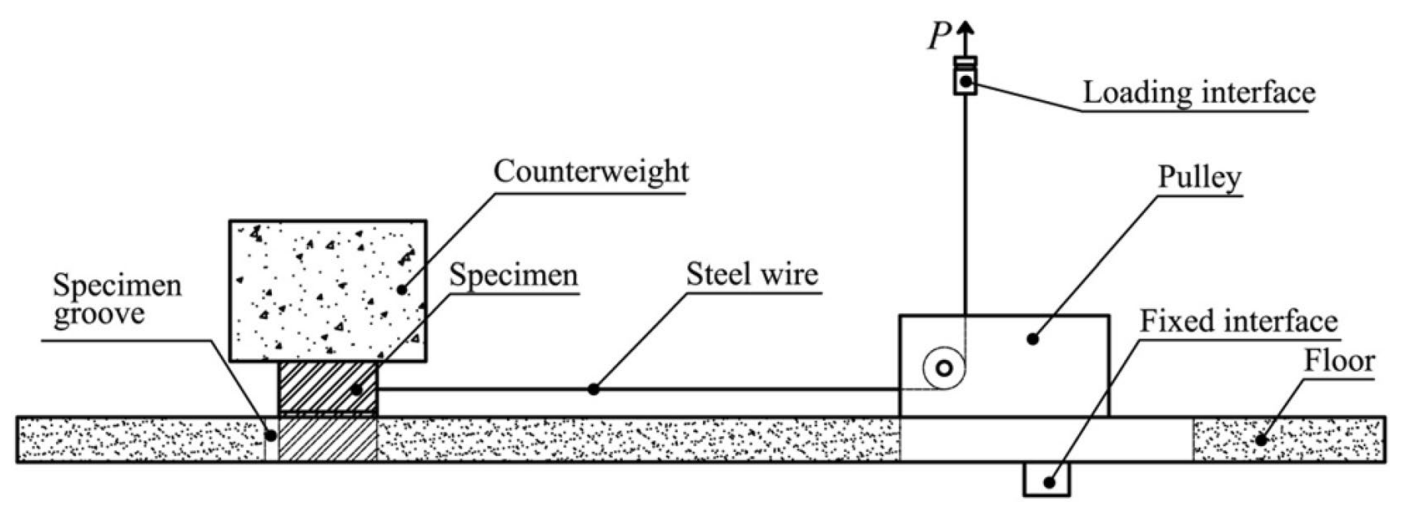

Fig. 4 Setup of measuring friction coefficient of the mortise-and-tenon joint

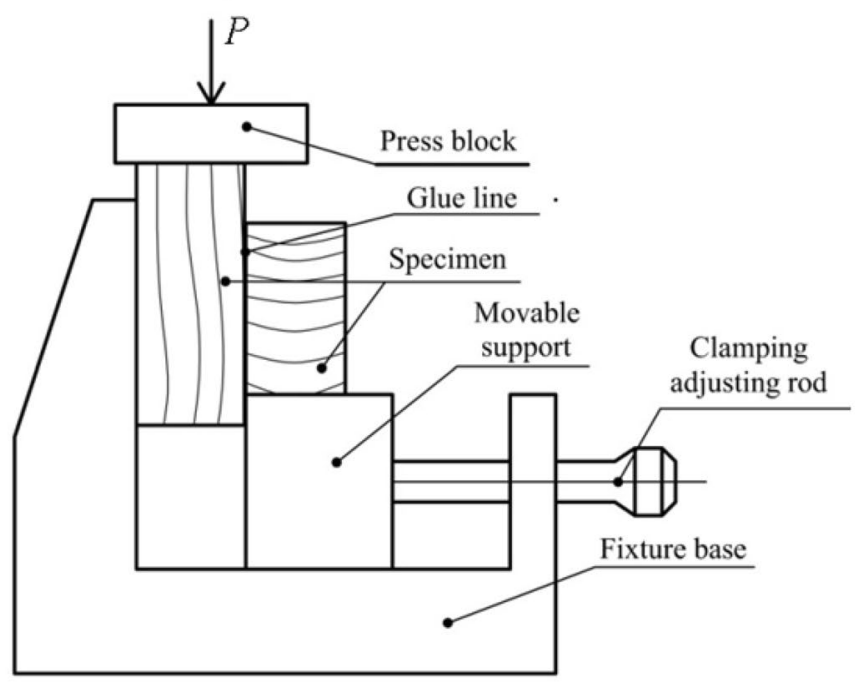

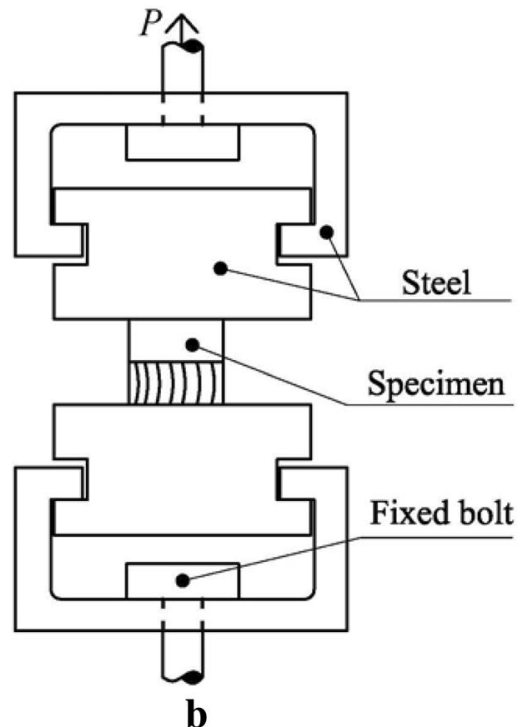

Fig. 5 Setup for measuring the $\mathbf{a}$ shear strength and $\mathbf{b}$ internal bond strength

where $F$ refers to the maximum force measured by machine, $N . p$ is the efficiency of the pulley (0.94). $m_{1}$ and $m_{2}$ refer to the weight of counterweight (2.5) and upper mortise (0.02), respectively, kg. $g$ is acceleration of gravity, $\mathrm{N} / \mathrm{kg}$.

\section{Shear and internal bond strength of glued joint}

Figure 5a shows the setup for measuring the shear strength of $G_{I}$ and $G_{\text {II }}$. It is worth paying attention not to fix the sample tightly by clamping the adjusting rod, but to make sure it can move smoothly when loaded $(P)$. The internal bond strength of glued joint in the flat area (Fig. 3c) was measured according to the procedure described in ASTM D1037-12 [16] and the setup is shown in Fig. 5b. All shear tests were performed on a
$20 \mathrm{kN}$ capacity universal testing machine at a loading rate of $1 \mathrm{~mm} / \mathrm{min}$ according to the procedures described in GB/T 1935-2009 [17]. The shear strength $G_{\mathrm{I}}$ and $G_{\text {II }}$ and internal bond strength were measured in 20 replications, respectively.

\section{Distribution of glue in the joint}

Fluorescence microscope (DM 50008B, Leica, Shanghai, China) was used to determine the actual distributions of glue in the joints. Toluidine blue solution with $0.5 \%$ solid content was used to stain all slices cut from block specimens (Fig. 3b, c). The glue line thickness of each specimen was measured 20 times by using Imagine $\mathrm{J} 2 \mathrm{x}$ software. 


\section{Withdrawal and bending loading capacities}

Figure $6 \mathrm{a}, \mathrm{b}$ shows the setup for determining the withdrawal and bending loading resistance capacities of the mortise-and-tenon joint, respectively. The loading rate of universal testing machine was $5 \mathrm{~mm} / \mathrm{min}$. The withdrawal and bending tests were repeated 20 times, respectively.

\section{Modeling}

Figure 7 shows the model created by ABQUAS software (ref) for evaluating the withdrawal and bending loading capacity of a mortise-and-tenon joint T-shaped specimen. Geometry, loading and boundary conditions of the model were based on Figs. 1 and 6. For beech wood, the required inputs for elastic properties were three moduli of elasticity, three moduli of rigidity, and six Poisson's

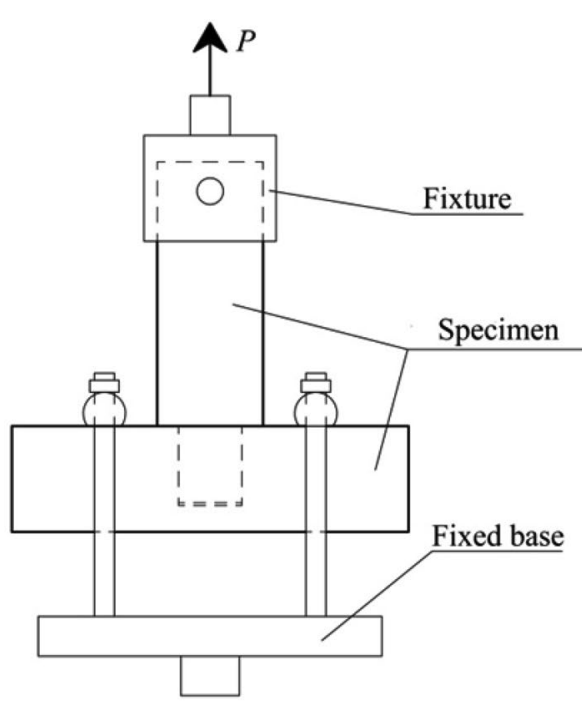

a

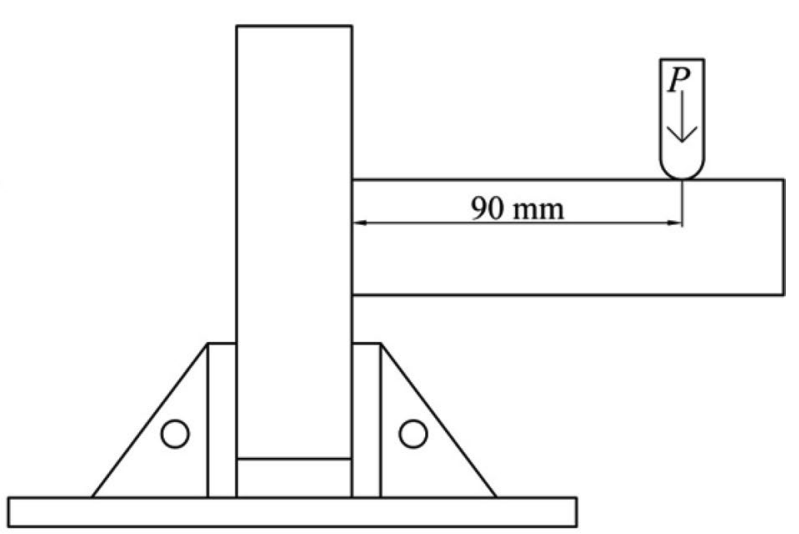

b

Fig. 6 Setup of determining the withdrawal (a) and bending (b) resistance capacity of the T-shaped joint

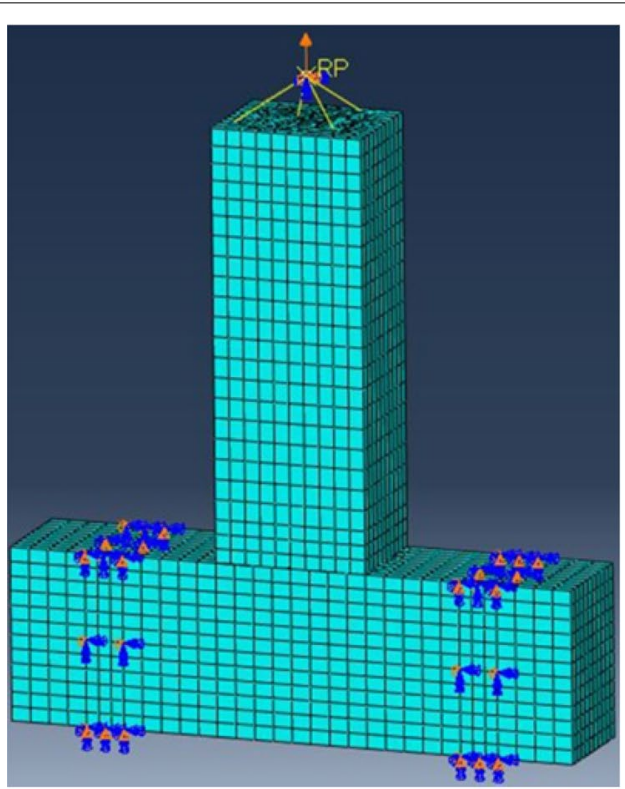

$\boldsymbol{a}$

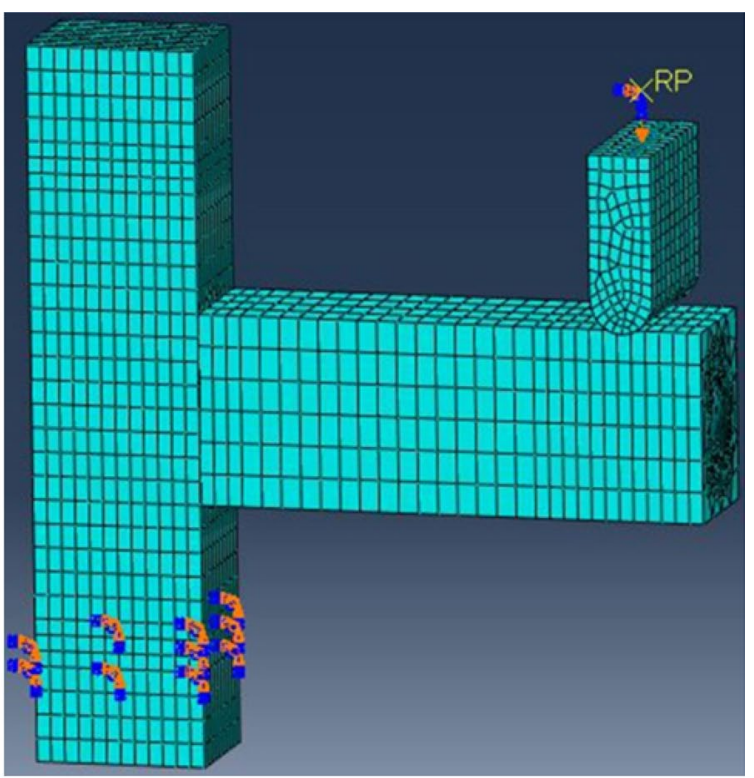

b

Fig. 7 FEMs of the T-shaped specimens for withdrawal resistance (a) and bending resistance (b) 
ratios as orthotropic material, and for glue line, they were one modulus of elasticity and one Poisson's ratio as isotropic material. Besides, material yield strengths required for inputs were compressive yield strengths of beech wood in longitudinal $(\mathrm{L})$, radial $(\mathrm{R})$, and tangential $(\mathrm{T})$ directions, respectively, and shear strength $\left(G_{\mathrm{I}}\right.$ and $\left.G_{\mathrm{II}}\right)$ of glue bonding. The elastic properties of beech wood were measured by strain gauges in compression tests in prophase study shown in Table $1[18,19]$, whereas the elastic properties of PVAc glue line were from literature [12], i.e., the modulus of elasticity was $460 \mathrm{MPa}$ and Poisson's ratio was 0.3. In general, 3D element, C3D8, was used to model beech wood materials; specifically, the element size of $1.4 \mathrm{~mm} \times 1.4 \mathrm{~mm} \times 1.4 \mathrm{~mm}$ was used for the material close to the contact surfaces of mortise-and-tenon and the element size of $5 \mathrm{~mm} \times 5 \mathrm{~mm} \times 5 \mathrm{~mm}$ was used for the rest of the joint member materials. Curve surfaces of the mortise-and-tenon joints were modeled using 3D element, C3D8, and surface-to-surface contact property was friction with their surface friction coefficient determined in this study. The reason for using nonbonding element for modeling curved surface was because in the actual experiment, it was observed that there was lack of adhesive in the contact surfaces of the curved area.

Cohesive element, COH3D8, with the size of $1 \mathrm{~mm} \times 1 \mathrm{~mm} \times 1 \mathrm{~mm}$, was used to model the glue line between flat surfaces of mortise-and-tenon joints, and the glue line thickness was set based on results determined by fluorescence microscope. Maximum damage was used as a stress criterion in the model, which is shown in Eq. 2. The initial damage will start, when the $\max$ is equal to 1 .

$$
\max \left\{\frac{\left\langle t_{\mathrm{n}}\right\rangle}{t_{\mathrm{n}}^{\mathrm{o}}}, \frac{t_{\mathrm{s}}}{t_{\mathrm{s}}^{\mathrm{o}}}, \frac{t_{\mathrm{t}}}{t_{\mathrm{t}}^{\mathrm{o}}}\right\}=1
$$

where $t_{\mathrm{n}}^{\mathrm{o}}, t_{\mathrm{s}}^{\mathrm{o}}$ and $t_{\mathrm{t}}^{\mathrm{o}}$ are maximum stresses of the internal bond, shear I and shear II directions, respectively.

A $30 \mathrm{~mm}$ displacement load was imposed on the stretcher to produce withdrawal (Fig. 6a) and bend (Fig. 6b) effects on the joint model, respectively. The total reaction force obtained at the reference points (RP) were the withdrawal and bending loading capacities of the modeled joint.

\section{Results and discussions}

\section{Friction coefficient of joint}

According to the testing method shown in Fig. 4, the friction coefficient was figured out by Eq. 1. The average friction coefficient of the mortise-and-tenon joint is 0.54 with coefficient of variance (COV) $7.62 \%$. Besides, the results were analyzed by analysis of variance (ANOVA) and all mean comparisons were performed at the $1 \%$ significance level using the protected least significant difference (LSD) multiple comparisons procedure. The results shows that the effect of grain orientations of tenon on friction coefficient is not statistically significant with $p$ value far more than 0.01 . Besides, Hu and guan [20] studied the influences of pressures and grain orientations on the friction coefficient of beech wood, and the results showed that the effects of pressure on the friction coefficient of wood were not considered to be statistically significant.

\section{Distributions of glue in joint}

Figure 8 shows the distributions of glue in the curve surfaces and flat surfaces of the joint, which indicates that glue was absent in the curve surface, while the distributions of glue in the flat surface was obvious. The results measured by fluorescence microscope shows the average thickness of glue line in the flat surface is $54.54 \mu \mathrm{m}$ with COV 18.44\%, which suggests that the thickness of

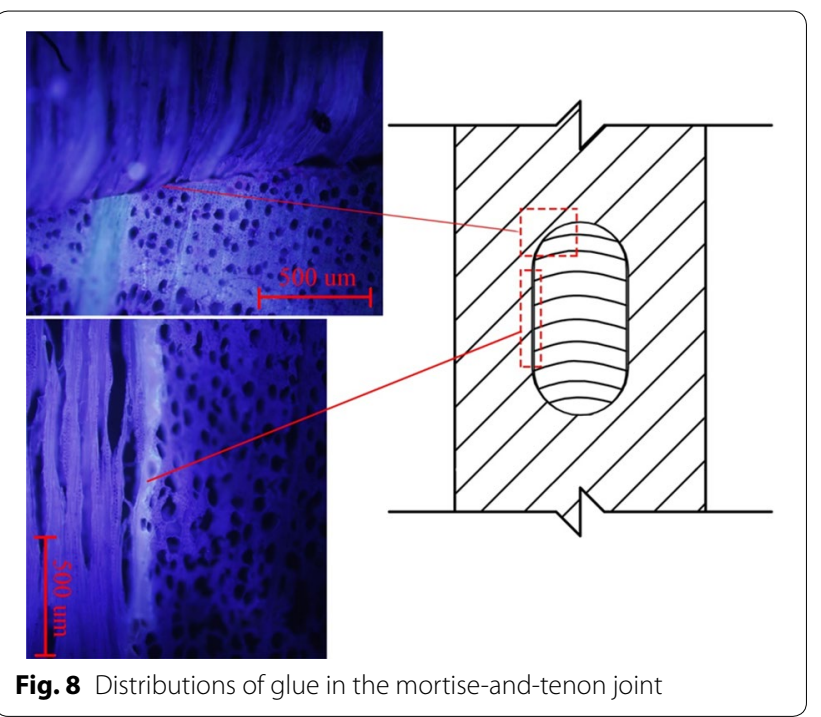

Table 1 Mechanical properties of beech wood [18, 19]

\begin{tabular}{|c|c|c|c|c|c|c|c|c|c|c|c|c|c|c|}
\hline \multicolumn{3}{|c|}{ Modulus of elasticity (MPa) } & \multicolumn{6}{|c|}{ Poisson's ratio } & \multicolumn{3}{|c|}{ Shear modulus (MPa) } & \multicolumn{3}{|c|}{ Yield strength (MPa) } \\
\hline$E_{\mathrm{L}}$ & $E_{\mathrm{R}}$ & $E_{\mathrm{T}}$ & $v_{\text {LR }}$ & $v_{L T}$ & $v_{R T}$ & $v_{T R}$ & $\mathrm{v}_{\mathrm{TL}}$ & $v_{R L}$ & $G_{\mathrm{LR}}$ & $G_{\mathrm{LT}}$ & $G_{\mathrm{RT}}$ & L & $\mathbf{T}$ & $\mathbf{R}$ \\
\hline 12,205 & 1858 & 774 & 0.502 & 0.705 & 0.526 & 0.373 & 0.038 & 0.078 & 899 & 595 & 195 & 42.51 & 4.49 & 9.83 \\
\hline
\end{tabular}


glue line in the flat surface of joint is not equal to the gap between mortise and tenon. This is consistent with the study of Džinčić and Živanić [14].

\section{Shear strengths of the glue joint}

Figure 9 shows the result of the shear strengths $\left(G_{I}\right.$ and $G_{\text {II }}$ of the joint, which suggests that the shear strength $G_{\text {I }}$ is a little bigger than that of $G_{I I}$. However, the results of ANOVA suggest that the difference between $G_{I}$ and $G_{I I}$ is not statistically significant with $p$ value $>0.01$. The internal bond strength of the joint in the flat area is $1.63 \mathrm{MPa}$ with COV $17.8 \%$.

\section{Comparison between the experiment and FEM}

Table 2 shows the comparison between the experiment and FEM in the withdrawal and bending states through determining the withdrawal and bending loading capacities of T-shaped specimens. It suggests that the results of FEM are well consistent with those of the experiment in withdrawal and bending states with ratios of 0.97 and 0.85 , respectively.

Figure 10 illustrates the failure mode of the tenon in the withdrawal state, which shows that the fracture of glue bonding only occurs in the flat surface of tenon, and also proves the distributions of glue only in the flat surface. However, the curve surfaces of tenon are smooth, which indicates that there is no glue in the curve surface. This phenomenon agrees with the results determined by microscope, and also confirms that the finite element model of the mortise-and-tenon joint built in this paper is reasonable.

Figure 11 shows the load-displacement curves of the experiment and FEM in the bending state. The whole trends of experiment and FEM are consistent with each other, i.e., in stage 1, the load increased rapidly; and then the load declined in stage $2(\mathrm{AB})$, because of

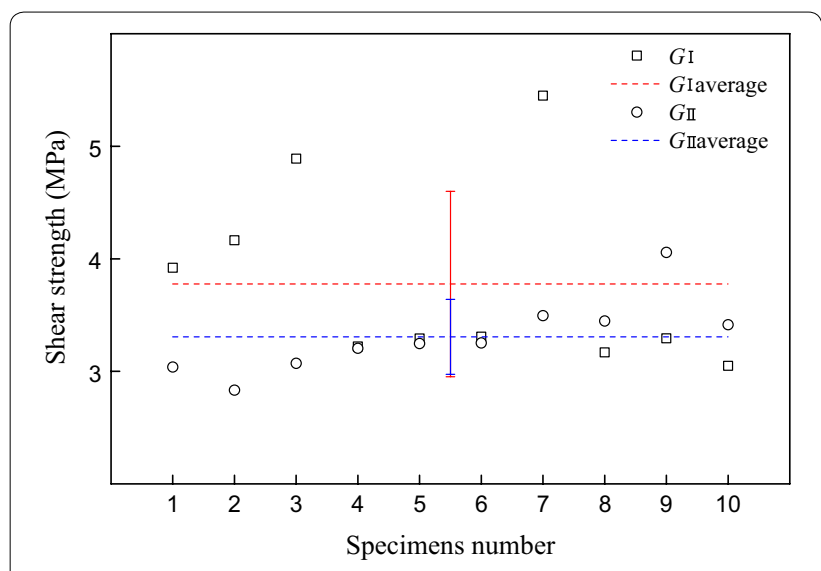

Fig. 9 Results of shear strength $G_{\mid}$and $G_{\|}$
Table 2 Comparison of withdrawal and bending load capacities of experiment and FEM

\begin{tabular}{lllrl}
\hline Loading types & Experiment & COV & FEM & Ratio \\
\hline Withdrawal $(N)$ & 5133 & 4.35 & 4998 & 0.97 \\
Bending $(N)$ & 1130 & 8.24 & 960 & 0.85 \\
\hline
\end{tabular}

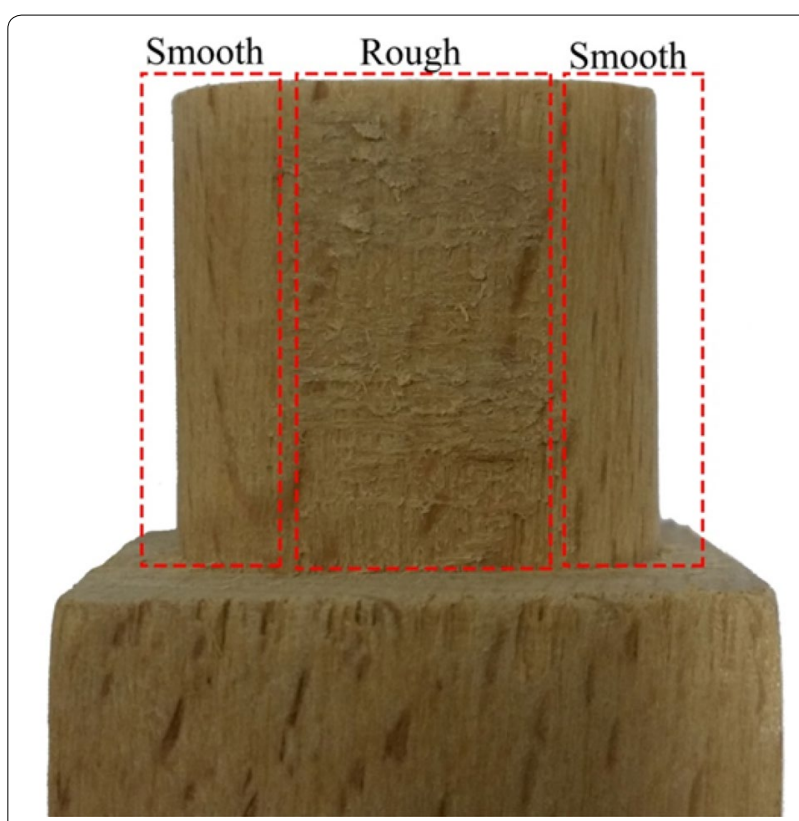

Fig. 10 Failure mode of the mortise-and-tenon joint after the withdrawal test

the failure of glue; in stage $3(\mathrm{BC})$, the load increased again until it reached the maximum load point $C$, where the wood began to fail; then the load dropped gradually in stage 4 . However, there are still differences between load-displacement curve of the experiment and FEM in details, i.e., in stage 2, the load drop of FEM is more than that of the experiment, and the displacement corresponding to the maximum load value of FEM was smaller than that of experiment, but the maximum load of experiment and FEM were very close. The reason why this phenomenon occurs is that the cohesive element (COH3D) used to simulate the glue and the element (C3D8) used to simulate the wood are deleted once the stress of the elements exceeds the shear strength of the glued joint and wood. The failure of the elements is more similar to brittle fracture [21]. However, it is known that the failure mode of wood compressed in transverse grain orientation is similar to ductile failure. The wood fibers still contribute to protect the strength of the wood member from dropping too fast, even though the wood member starts failing. 


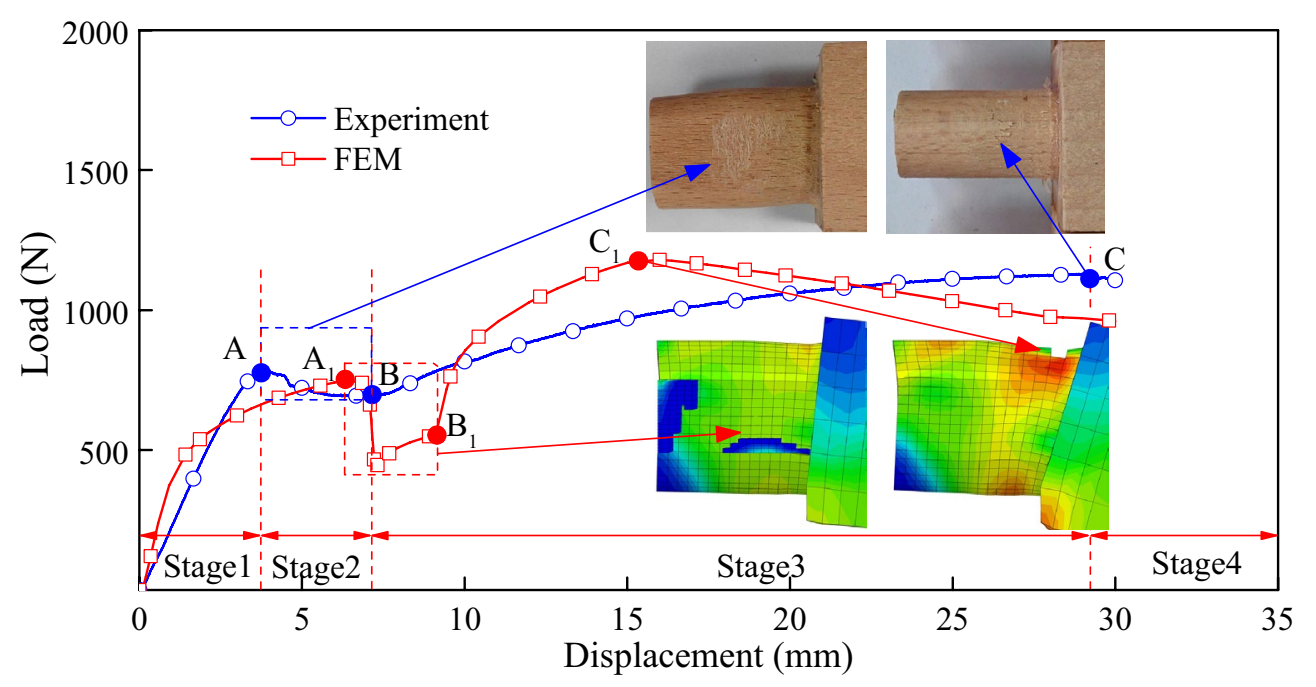

Fig. 11 Comparison between the experiment and FEM in the bending state

Further study will be focused on finding a more ductile element to simulate the mortise-and-tenon joint.

\section{Conclusions}

The following conclusions can be drawn according to the results of the experiment and FEM:

1. The method used to measure the friction coefficient of the joint is effective, and the average friction coefficient of beech wood mortise-and-tenon joint is 0.54 .

2. The distributions of glue in the mortise-and-tenon joint can be determined by fluorescence microscope clearly. Specifically, the thickness of the glue line in the flat surface is $54.54 \mu \mathrm{m}$, while glue was absent in the curve surface of the joint.

3. The procedures applied to process the specimens and measure the shear strengths of the mortiseand-tenon joint are valid, and the difference of shear strength $G_{\mathrm{I}}$ and $G_{\mathrm{II}}$ is not statistically significant.

4. The results of the finite element model are well consistent with those of the experiments in withdrawal and bending loading capacities of the mortise-andtenon joint T-shaped specimens.

In conclusion, the methods used in this paper can be applied to measure the distribution of glue, friction coefficient and strengths of the joint. In addition, the finite element model of the mortise-and-tenon joint can be applied to the structure design of wood furniture and wooden constructions.

\section{Abbreviations}

FEM: finite element method; PVAc: polyvinyl acetate; L: Iongitudinal; R: radial; T: tangential; RP: reference point; COV: coefficient of variance; ANOVA: analysis of variation; LSD: least significant difference.

\section{Authors' contributions}

All authors materially participated in the research and article preparation. Both authors read and approved the final manuscript.

\section{Acknowledgements}

The authors thank the support of a project funded by A Priority Academic Program Development of Jiangsu Higher Education Institutions (PAPD).

\section{Competing interests}

This manuscript has not been submitted to any of the other journals and has not been published previously (partly or in full). Its publication is approved by all authors and tacitly or explicitly by the responsible authorities where the work was carried out. There are no competing interests in this manuscript.

\section{Availability of data and materials}

The data are available if needed.

\section{Funding}

This work was supported by a project funded by A Priority Academic Program Development of Jiangsu Higher Education Institutions (PAPD).

\section{Publisher's Note}

Springer Nature remains neutral with regard to jurisdictional claims in published maps and institutional affiliations.

Received: 25 September 2018 Accepted: 6 March 2019

Published online: 12 March 2019

\section{References}

1. Tankut AN, Tankut N (2005) The effects of joint forms (shape) and dimensions on the strengths of mortise and tenon joints. Turk J Agric For 29:493-498

2. Shanks JD, Chang WS, Komatsu K (2008) Experimental study on mechanical performance of all-softwood pegged mortise and tenon connections. Biosyst Eng 100:562-570 
3. Eckelman CA (1971) Bending strength and moment rotation characteristics of two-pin moment resisting dowel joints. Forest Prod J 21(3):35-39

4. Feio AO, Lourenço PB, Machado JS (2014) Testing and modeling of a traditional timber mortise and tenon joint. Mater Struct 47:213-225

5. Smardzewski J, Lewandowski W (2014) Elasticity modulus of cabinet furniture joints. Mater Des 60(8):260-266

6. Eckelman CA (1968) Furniture frame analysis and design. PhD thesis, Purdue University, West Lafayette, IN

7. Gavronski T (2006) Rigidity-strength models and stress distribution in housed tenon joints subjected to torsion. Wood Technol 9(4):32

8. Çolakoglu MH, Apay AC (2012) Finite element analysis of wooden chair strength in free drop. Int J Phys Sci 7(7):1105-1114

9. Smardzewski J (2008) Effect of wood species and glue type on contact stresses in a mortise and tenon joint. J Mech Eng Sci 222(12):2293-2299

10. Silvana P, Smardzewski J (2010) Effect of glue line shape on strength of mortise and tenon joint. Drvna Ind 61(4):223-228

11. Derikvand M, Dalvand M, Maleki S, Ebrahimi G (2015) Numerical analysis of semi-rigid furniture connections using FEM. In: The XXVIITH international conference research for furniture industry. Ankara, Turkey, 17-18 September 2015, pp 28-38

12. Kasal A, Smardzewski J, Kuskun T, Erdil YZ (2016) Numerical analyzes of various sizes of mortise and tenon furniture joints. BioResources 11(3):6836-6853

13. Kılıç K, Kasal A, Kuşkun T, Acar M, Erdil YZ (2018) Effect of tenon size on static front to back loading performance of wooden chairs in comparison with acceptable design loads. BioResources 13(1):256-271
14. Džinčić I, Živanić D (2014) The influence of fit on the distribution of glue in oval tenon mortise joint. Wood Res-Slovakia 59(2):297-302

15. ASTM D 4442-92 (2001) Standard test methods for direct moisture content measurement of wood and wood-base materials. American Society for Testing and Materials, West Conshohocken

16. ASTM D1037 (2012) Standard test methods for evaluating properties of wood-base fiber and particle panel materials. ASTM International, West Conshohocken

17. CNS GB/T 1935 (2009) Method of testing in compressive strength parallel to grain of wood. China National Standard, Beijing (In Chinese)

18. HuWG, Guan HY (2017) Study on elastic modulus of beech in different stress states. J Forest Eng 2(06):36-41 (in Chinese with summary in English)

19. Hu WG, Guan HY (2017) Investigation on withdrawal capacity of mortise and tenon joint based on friction properties. J Forest Eng 2(04):158-162 (in Chinese with summary in English)

20. Hu WG, Guan HY (2017) Experimental and numerical study on optimization design of stretcher positions. Wood Res Slovakia 62(4):575-586

21. Hu WG, Guan HY, Zhang JL (2018) Finite element analysis of tensile load resistance of mortise-and-tenon joints considering tenon fit effects. Wood Fiber Sci 50(2):121-131

\section{Submit your manuscript to a SpringerOpen ${ }^{\circ}$ journal and benefit from:}

- Convenient online submission

- Rigorous peer review

- Open access: articles freely available online

- High visibility within the field

- Retaining the copyright to your article

Submit your next manuscript at $\boldsymbol{\nabla}$ springeropen.com 